0271-5198(94)00086-7

\title{
CONTENTS OF BIORHEOLOGY
}

VOLUME 31, NUMBER 5

R. P. Tomkiewicz, A. Biviji and M. King

\section{S. Hashimoto}

A. Delfino, J. E. Moore, Jr. and J.-J. Meister

S. K. Wang and N. H. C. Hwang

P. D. Ballyk, D. A. Steinman and C. R. Ethier

E. Muralidharan

\section{SEPTEMBER-OCTOBER 1994}

\author{
Papers
}

511 Effects of oscillating air flow on the rheological properties and clearability of mucous gel simulants

521 Clot growth under periodically fluctuating shear rate

533 Lateral deformation and movement effects on flow through distensible tube models of blood vessels

549 On the transport of a suspended particle in flow through the entrance region of a tube

565 Simulation of non-Newtonian blood flow in an end-to-side anastomosis

587 Simultaneous determination of hematocrit, aggregate size and sedimentation velocity by $\mathrm{He}-\mathrm{Ne}$ laser scattering

601 Contents of Clinical Hemorheology, Volume 14, Number 2 